\title{
Index to advertisers
}

c 3 Alden Electronics, Inc.

263 Belfort Instrument

c 4 The Bendix Corporation

c 2 EG\&G, Inc.

279 John Wiley and Sons, Inc.

282 Meteorology Research, Inc.

258 Science Associates

225 Technology Service, Inc.

281 Texas Electronics

AMS Notices (Publications, Preprints, etc.)

272 Preprint Volume, Fourth Conference on Weather Modification

286 Macelwane, Orville, Hanks Scholarships

294 Preprint Volume, Sixth Conference on Aerospace and Aeronautical Meteorology

338 Preprint Volume, Conference on Cloud Physics

350 Fifth Conference on Weather Forecasting and Analysis

350 Employment Announcements

The deadline for advertising insertion orders is the 15th, two months prior to date of issue. Orders received after deadline are subject to space availability. Deadline for copy and/or plate is the lst day of month, one month prior to date of issue. For advertising information contact: Evelyn Mazur, American Meteorological Society, 45 Beacon Street, Boston, Mass. 02108. Tel. 617-227-2425.

\section{employment announcements}

The American Meteorological Society issues employment announcements monthly, setting forth opportunities for positions in the atmospheric and oceanographic fields. The employers describe the prerequisites and requirements for the openings.

Members and nonmembers of the AMS may subscribe to the announcements. The subscription price per annum for twelve monthly issues is $\$ 5$ for AMS Members and Associate Members, $\$ 2$ for AMS Student Members, and $\$ 25$ for non-members.

The purpose of the Employment Bulletin is to provide a means by which those seeking positions in the atmospheric and related fields and those requiring personnel to fill such openings may have a convenient means of communication. Organizations that wish to avail themselves of this service should contact the American Meteorological Society for details and charges.

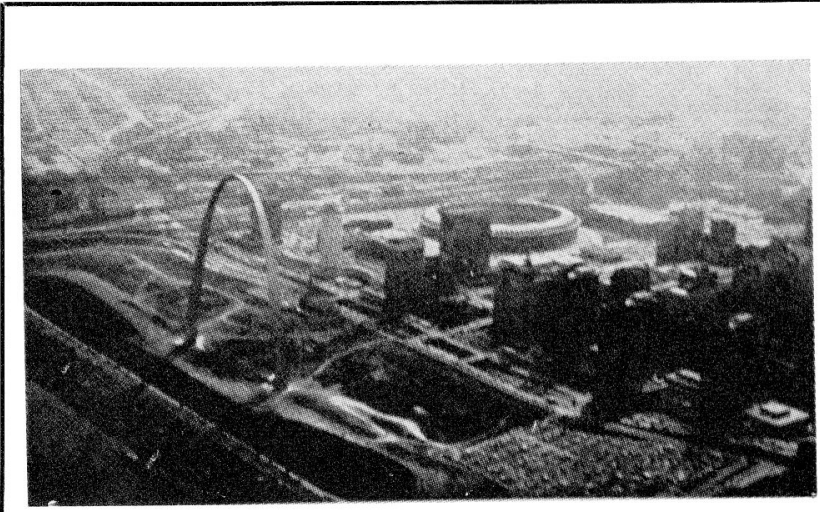

FIFTH CONFERENCE ON

WEATHER FORECASTING AND ANALYSIS

\section{AMERICAN METEOROLOGICAL SOCIETY}

MARCH 4-7, 1974

ST. LOUIS, MO.

Preprints of approximately 68 papers presented at the AMS Fifth Conference on Weather Forecasting \& Analysis, March 4-7, 1974 at the Sheraton-Jefferson Hotel, St. Louis, Mo. are available in a bound volume.

Papers were presented on extratropical analysis and forecasting with emphasis on shortrange forecasting. Special sessions were scheduled to include topics on: the role of the meteorologist in issuing public news releases on weather disasters of unique national significance; formulation, dissemination, understanding and use of weather forecasting; aviation weather.

The papers are arranged under the following topics:

Weather Systems of the Future - Weather Forecasts-Their Formulation, Expression, Dissemination and Use - Satellite Meteorology and Audience Participation Workshop - Precipitation and Clouds - Mesoscale Forecasting and Analysis - Synoptic Scale Forecasting and Analysis - Air Pollution and Urban Effects - Applications and Deficiencies of Synoptic Meteorological Material - Ceiling and Visibility - Boundary Layer Phenomena - Convective Activity

291 Pages

$\$ 15$ AMS Members $\$ 20$ Nonmembers

Send orders and remittance to:

AMERICAN METEOROLOGICAL SOCIETY

45 Becon Street

Boston, Mass. 02108 